eCoaching: The Effects on Co-Teachers' Planning and Instruction

By: Donna M. Ploessl, Marcia L. Rock

Ploessl, D.M., \& Rock, M.L. (2014). eCoaching: The Effects on Co-Teachers' Planning and Instruction. Teacher Education and Special Education, 37(3), 191-215. doi:

$10.1177 / 0888406414525049$

Made available courtesy of Sage Publications: $\underline{\text { http://dx.doi.org/10.1177/0888406414525049 }}$

***(C) Teacher Education Division of the Council for Exceptional Children. Reprinted with permission. No further reproduction is authorized without written permission from Teacher Education Division of the Council for Exceptional Children \& Sage Publications. This version of the document is not the version of record. Figures and/or pictures may be missing from this format of the document. $* * *$

\begin{abstract}
:
Although co-teaching has become a popular approach to special education service provision in inclusive classrooms, practitioners have struggled to carry it out well. One suggestion for improvement has been to provide co-teachers with training that includes coaching. In this study, we used single-case (ABAB) withdrawal design, to investigate the effects of eCoaching, delivered through online bug-in-ear technology, on co-teachers as they planned and carried out co-teaching. Participants included three co-teaching dyads $(n=6)$; each comprised of one general and one special educator. Visual inspection of graphed data along with quantitative analysis (i.e., percentage of non-overlapping data) confirmed that eCoaching increased participants' use of varied co-teaching models and student-specific accommodations, while coteachers' interviews and students' time samples verified social validity. Taken together, these findings lead to better understanding of the benefits and limitations of eCoaching with coteachers.
\end{abstract}

Keywords: eCoaching | bug in ear | co-teaching | professional development | planning and instruction | teacher preparation policy/service delivery

\title{
Article:
}

In an era of increased inclusive practices and teacher accountability, the number of general and special education teachers partnering in efforts to improve students with disabilities' access, progress, and achievement in the general curriculum continues to rise. Volonino and Zigmond (2007) noted that co-teaching has been identified as the most common approach to special education service provision in inclusive classrooms. L. Cook and Friend (1995) define coteaching as "two or more professionals jointly delivering substantive instruction to a diverse, or blended, group of students in a single physical space” (p. 1). Although co-teaching has gained popularity, two published syntheses—one quantitative (Murawski \& Swanson, 2001) and one 
qualitative (Scruggs, Mastropieri, \& McDuffie, 2007)—confirm only moderate success, prompting many to question the quality with which it has been implemented (Spooner, Algozzine, Wood, \& Hicks, 2010).

\section{The Role of Training in Co-Teaching}

Friend, Cook, Hurley-Chamberlain, and Shamberger (2010) provided specific recommendations for co-teaching training. Dettmer, Thurston, and Dyck (2005) pointed out that one of the greatest obstacles co-teachers face is lack of training and preparation for their new roles. Teachers also identified the lack of training (Dettmer et al., 2005; Keefe \& Moore, 2004), the need for greater skill development (Curtin, 1998), and the need for different training methods (Scruggs et al., 2007) as problems adversely affecting co-teaching practice. Thus, efforts to improve the quality and success of co-teaching may hinge, in part, on training (Murawski, 2008).

Pancsofar and Petroff (2013) found positive relationships between the frequency of co-teaching training and desired teacher outcomes. Teachers who had more in-service opportunities demonstrated higher levels of interest in co-teaching, held more positive attitudes toward coteaching, and reported greater confidence in their co-teaching abilities. Although preliminary, these findings confirm that frequent in-service training may alleviate some longstanding attitudinal barriers encountered by co-teachers.

\section{Characteristics of Effective Co-Teaching Training}

In general, effective professional development offers teachers not only explicit instruction in evidence-based practices through modeling and demonstration but also opportunities for guided practice with feedback (Joyce \& Showers, 2002). The latter of which includes coaching provided by experts (Leko \& Brownell, 2009; Sindelar, Brownell, \& Billingsley, 2010). Unfortunately, current approaches to in-service training often do not include guided practice with feedback or coaching. Instead, workshops and webinars remain popular approaches, stuffed into teachers' busy schedules like “mortar into bricks," just enough to put pieces together yet not enough to give the training strength or meaning in practice (Rooney, 2007). Specifically, traditional professional development without coaching means little to no transfer to practice yet with coaching the transfer to practice is high (Joyce \& Showers, 2002).

Specific to training in co-teaching, Friend et al. (2010) also suggest that professional development should include joint participation and coaching. Regrettably, Fennick and Liddy (2001) found that when co-teachers did receive training, the benefits often went unrealized because it was too brief and too limited. Taken together, one can conclude that professional development for co-teachers should include intensive training and feedback in situ. A practice frequently referred to as job embedded professional development (Croft, Coggshall, Dolan, Powers, \& Killion, 2010). 
In addition to improving the pedagogy of professional development, a need also exists to strengthen the content of co-teaching training. Obviously, co-teaching training should target the knowledge, skills, and dispositions that support quality implementation. Recent findings by Brinkmann and Twiford (2012) shed additional light on this topic. Based on focus group interviews conducted with practicing elementary general and special education teachers who cotaught in inclusive classrooms, they concluded that successful partners possessed a variety of skills, including classroom management, collaborative lesson planning, communication, data collection, interpersonal skills, differentiation of instruction, and self-advocacy.

Because problems associated with co-teaching practice are well documented, the scope of professional development should include training in potential solutions. Results from WaltherThomas and Bryant (1996) underscore the importance of providing additional training on coteaching models, problem solving, and planning. Studies conducted by Dieker (2001), Moin, Magiera, and Zigmond (2008), and Gurgur and Uzuner (2011) also emphasize a need for coteachers to learn more about effective and efficient use of planning time. Some researchers (Moin et al., 2008; Murawski, 2008; Scruggs et al., 2007) report an over reliance on one coteaching model (i.e., teach and assist), which suggests further training regarding the special educator's instructional roles and responsibilities may be beneficial. Relatedly, others (Harbort et al., 2007; Weiss \& Lloyd, 2002; Zigmond \& Baker, 1995) find that the special educator often serves as a "manager" of behavior, rather than a co-instructor, which points to a need for increased training in positive behavioral interventions and supports (PBIS, that is, classroom/behavior management). Finally, the lack of specialized instruction (including accommodations and modifications) provided to students with disabilities in co-taught classrooms (see Baker \& Zigmond, 1995; Magiera \& Zigmond, 2005; Scruggs et al., 2007) indicates a potential gap in understanding that could be ameliorated by additional co-teaching training.

\section{Findings From Research in Co-Teaching Training}

Although the professional literature is rich with descriptions of co-teaching, relatively little has been published on performance based training outcomes. Our review of the relevant literature produced four published studies - two of which were conducted at the state level (Bryant Davis, Dieker, Pearl, \& Kirkpatrick, 2012; Pearl, Dieker, \& Kirkpatrick, 2012), one at the district level (Walsh, 2012), and one at the classroom level (Scheeler, Congdon, \& Stansbery, 2010).

State level. Through the Arkansas Department of Education Co-Teaching Project, Pearl et al. (2012) employed a variety of comprehensive professional development tactics (i.e., traditional workshops, web resources, interactive webinars, on-site coaching, and evaluative feedback) to provide co-teaching training to participants in 143 school districts. The results were positive. After 5 years, they reported improvements in building-level supports, ratings of co-teaching partnerships, and grades of students with disabilities in co-taught classrooms. 
In a related study, also carried out in collaboration with the Arkansas Department of Education Co-Teaching Project, Bryant Davis et al. (2012) conducted a closer examination of training outcomes. Over a 3-year period, they provided professional development to participants in coplanning, co-teaching, and evaluation of co-teaching models through annual workshops and follow-up support (i.e., monthly online webinars, resource webpage, e-mail or telephone consultation, limited number of on-site visits by request). Participants also received a free coteaching lesson plan book (Dieker, 2002). Based on content analysis of 755 days of middle school co-teachers' lesson plans, Bryant Davis et al. reported mixed results. Although a variety of co-teaching models were planned, “teach and assist” dominated. In approximately 65\% of plans, special educators included accommodations and modifications that aligned with general educators’ plans. That means nearly a third (29\%) of plans reflected lack of planning or misalignment. Only 29\% illustrated technology use (i.e., 26\% low tech, 3\% high tech). Moreover, a mere 8\% included positive behavior interventions and support strategies (i.e., 2\% reminding students of rules, $7 \%$ changing seats, $0 \%$ self-monitoring). Finally, because Bryant Davis and her colleagues did not collect data on co-teaching practice, whether participants actually carried out what was planned remains unknown.

District level. Walsh (2012) described a system wide approach to co-teaching training in one Maryland school district and reported favorable outcomes over time. In 2008-2009, teachers in eight elementary schools received yearlong professional development through The Designing Quality Inclusive Education (DQIE) model. The model included instructional coaching for coteachers. In those schools, students with disabilities increased reading and math proficiency by $11 \%$ and $14.5 \%$ respectively - improvements that were attributed, in part, to the coaching coteachers received. In other schools, the performance of students with disabilities paled in comparison (i.e., 1\% increase in reading, no change in math). Based on these and other improvements in student achievement, the Maryland State Department of Education developed a co-teaching network so other school districts could access the professional development model (DQIE) Walsh described, created, and used successfully.

Classroom level. Scheeler et al. (2010) investigated the effects of peer coaching through onsite bug-in-ear (BIE) technology with three dyads of co-teachers. In this study, practicing co-teachers successfully coached one another in the completion of three-term contingency (TTC) trials, while carrying out the one teach, one assist model. To do so, the teacher who led instruction wore the BIE earpiece and received immediate, discreet feedback from his or her partner who assumed the assistant role. The co-teaching partners switched roles midway through each lesson. With improvements demonstrated after only three sessions, Scheeler and her colleagues concluded this approach was effective in increasing each teacher's percentage of completion of TTC trials to the criterion set by the researchers. In terms of social validity, participants indicated that the BIE device was an acceptable, non intrusive, and efficient means to deliver feedback in real time. 


\section{Taking Co-Teaching Training Into the Digital Age}

For over 50 years, researchers in a variety of disciplines have investigated BIE devices, such as the one used in the abovementioned study, as a way to promote practice of newly acquired skills (Korner \& Brown, 1952). Recent technology innovations have afforded teacher educators/trainers new means of providing teachers with immediate feedback online, in real time. A group of researchers (Rock et al., 2012; Rock et al., 2009) developed an advanced online BIE system based on mobile technology and interactive video conferencing-bringing the BIE into the cyber age. Their online alternative consists of four affordable, off the shelf components (i.e., a webcam, a Bluetooth headset, a Bluetooth adapter, and Skype) that are added easily to a desk or laptop computer. Rock and her colleagues provided what was initially dubbed Virtual Coaching (now referred to as eCoaching) through advanced online BIE technology to practicing teachers enrolled in two different cohorts of a federally funded personnel development program. Results from these studies (see Rock et al., 2012; Rock et al., 2009) confirmed statistically significant increases in participants' use of evidence-based instructional and behavioral strategies.

\section{Moving Forward: The Purpose of the Current Study}

Levin, O’Donnell, and Kratochwill (2003) identified four stages of educational research that included (1) initial hypothesis and exploration, (2) controlled experiments and demonstrations, (3) randomized field trials, and (4) identification of variables adopted for practice. To date, the bulk of the extant co-teaching research reflects Stage 1. Clearly, a need exists for co-teaching researchers to undertake more second-, third-, and fourth-stage studies.

Our purpose in conducting this Stage 2 investigation was to advance the evidence base in professional development training for co-teachers using the online eCoaching system developed and researched by Rock and her colleagues (2009) and Rock et al. (2012). Specifically, we examined the effects of eCoaching on co-teaching partners' planned and implemented coteaching models, the number and types of student-specific accommodations and modifications teachers planned and implemented, and the positive behavioral supports and interventions that co-teachers planned for and carried out during instruction. To do this, we focused our investigation on in-service teachers new to co-teaching, who could benefit from the added support of an expert eCoach, as they initiated co-teaching in their respective classrooms. Below are the specific research questions we sought to answer.

Research Question 1: How does eCoaching influence how co-teachers plan for and carry out varied co-teaching models, student-specific accommodations and modifications, and PBIS?

Research Question 2: How does eCoaching impact (i.e., benefit or disrupt) coteachers and their P-6 students?

\section{Method}




\section{Design}

We used a single-case withdrawal (ABAB) within-participants research design (Barlow, Nock, \& Hersen, 2009; Kazdin, 2011) to evaluate the effects of eCoaching on co-teachers' planning and instruction. Because of concerns about reversibility, we considered a multiple baseline design. In most cases, when using a withdrawal design, one would expect to see a reversal of behavior during the second baseline condition (Barlow et al., 2009; Kazdin, 2011). Kennedy (2005), however, cautioned that in the case of learned skills, especially with adult participants, it might be difficult to reverse the effect of the intervention. Nonetheless, we opted for a withdrawal, rather than a multiple baseline design as the reversal design is potentially more powerful for determining a functional relationship between the independent and dependent variables (eCoaching and teacher behaviors).

Table 1. Make-Up of Co-Teaching Pairs.

\begin{tabular}{|c|c|c|c|c|c|c|}
\hline $\begin{array}{l}\text { Co- } \\
\text { teaching } \\
\text { dyads }\end{array}$ & $\begin{array}{l}\text { General } \\
\text { education } \\
\text { teacher }\end{array}$ & $\begin{array}{l}\text { Years of } \\
\text { experience/co- } \\
\text { teaching } \\
\text { experience }\end{array}$ & Ethnicity & $\begin{array}{l}\text { Special } \\
\text { education } \\
\text { teacher }\end{array}$ & $\begin{array}{l}\text { Years of } \\
\text { experience/co- } \\
\text { teaching } \\
\text { experience }\end{array}$ & Ethnicity \\
\hline Pair 1 & $\begin{array}{l}\text { Non- } \\
\text { project } \\
\text { graduate }\end{array}$ & $10 /<1$ & $\begin{array}{l}\text { African } \\
\text { American }\end{array}$ & $\begin{array}{l}\text { Project } \\
\text { graduate }\end{array}$ & $15 /<1$ & $\begin{array}{l}\text { African } \\
\text { American }\end{array}$ \\
\hline Pair 2 & $\begin{array}{l}\text { Project } \\
\text { graduate }\end{array}$ & $15 /<1$ & $\begin{array}{l}\text { African } \\
\text { American }\end{array}$ & $\begin{array}{l}\text { Non- } \\
\text { project } \\
\text { graduate }\end{array}$ & $1 /<1$ & Caucasian \\
\hline Pair 3 & $\begin{array}{l}\text { Project } \\
\text { graduate }\end{array}$ & $5 /<1$ & Caucasian & $\begin{array}{l}\text { Non- } \\
\text { project } \\
\text { graduate }\end{array}$ & $28 /<1$ & Caucasian \\
\hline
\end{tabular}

\section{Participants}

In this study, we used purposive convenience sampling (Kazdin, 2011). To do so, we recruited six practicing teachers to form three co-teaching dyads $(n=6)$. Three of these six were recent graduates of a federally funded personnel development program that included immersion in 2 years of eCoaching. These participants had each completed the same 3-credit hour graduatelevel course that provided training in co-teaching and a practicum (i.e., field experience). We (i.e., first and second authors) co-taught this course. The three participants identified a voluntary partner who had successfully completed district-level professional development training for co-teachers. In the end, each co-teaching pair was comprised of a certified general education teacher and a certified special education teacher (see Table 1) who were responsible for serving students who received special education services under the Individuals With Disabilities Education Improvement Act (2004) in an inclusive general education classroom. Prior to implementation, 
we secured school administrators’ permission for the teachers to participate in the study and university IRB approval.

\section{Setting}

The participants taught at three public elementary schools in the Southeast. School 1 served 273 students in Grades Pre-K-5. The school's enrollment was 100\% African American, and 97\% of the students met requirements for free or reduced lunch. School 2 served 250 students in Grades Pre-K-5. This schools enrollment consisted of 99\% African American and $<1 \%$ Caucasian students. Ninety percent of enrolled students met state requirements for free or reduced lunch. School 3 served 316 students in Grades Pre-K-5. School enrollment was 40\% African American, 20\% Latino, and 40\% Caucasian students. Sixty-nine percent of students met requirements for free or reduced lunch. Teacher participants taught in second and third-grade inclusive classrooms within each school. The coach, who was the first author, observed classrooms and provided eCoaching from a private, remote office.

\section{Apparatus}

Throughout all phases of the study, the eCoach and co-teaching participants used an online platform developed and tested from 2007 to present by Rock and her colleagues (see Rock, Zigmond, Gregg, \& Gable, 2011, for specifications) to meet electronically. The eCoaching technology made use of participants' existing classroom computer and Internet connection. During baseline conditions (Phases 1 and 3), when no eCoaching was provided to participants, we used only the interactive video conferencing (IVC) component (i.e., Skype). When eCoaching was underway during intervention conditions (Phases 2 and 4), we used the coteachers' existing IVC equipment with advanced online BIE technology so we could provide feedback immediately in situ (i.e., while the co-teachers were teaching). During a co-taught lesson, one participant wore the Bluetooth to receive discreet, immediate feedback from the eCoach. During the next lesson, the other participant in the co-teaching pair wore the Bluetooth. The participants secured the equipment needed, including the advanced online BIE technology, through their previous involvement in a federally funded personnel development grant. As was the case in Rock et al. (2012), we used the Call Recorder for Mac, a plug-in for Skype that enables video call recording, to electronically capture each coplanning and teaching session. Also, we saved the recorded video files on an external hard drive for data extraction and later analysis. In accord with University IRB protections, we secured the external hard drive in a locked office.

\section{Independent Variable}

In this study, we investigated the effects of one independent variable, eCoaching, provided to coteaching participants during co-planning and co-instruction. As in Rock et al. (2009) and Rock et al.'s (2012) previous studies, the eCoaching intervention we used was comprised of differing types of immediate feedback. Reinforcement or positive feedback consisted of statements that 
provided "social praise for performing specific teaching behaviors" (Scheeler, Ruhl, \& McAfee, 2004, p. 399). Corrective feedback included statements related to the "type and extent of error and specific ways to correct the error" (p. 399). Questioning feedback was defined as "a sentence posed in interrogative form to get information or to clarify specific teaching behaviors" (Random House Unabridged Dictionary, 2006, in Rock et al., 2009, p. 72). And instructional feedback was defined as "[when] objective information related to predetermined specific teaching behaviors is offered” (Scheeler et al., 2004, p. 399).

Based on findings from past research, the eCoach provided targeted feedback to the co-teaching partners during planning and while teaching in three areas: (a) co-teaching models, (b) studentspecific accommodations and modifications, and (c) PBIS strategies during the two intervention

phases. For co-teaching models, the feedback provided through the eCoaching was limited to (a) implementation of different models related to the content of the lesson, (b) implementation of different models related to the lesson cycle, and (c) fidelity to variety of models. eCoaching feedback that targeted student-specific accommodations was limited to (a) alternate methods for responses (e.g., verbal responses, dictation to a scribe), (b) alternate modes of presentation (e.g., reduced number of items per page; National Center for Learning Disabilities, 2006), and (c) use of color coding strategies (Gould \& Vaughn, 2000). Feedback that targeted student-specific modifications was limited to (a) targeting lower level skills and (b) individualizing curriculum materials (Smith, Polloway, Patton, \& Dowdy, 2008). Feedback targeting PBIS was limited to (a) specific, descriptive praise (Simonsen, Myers, \& DeLuca, 2010) and (b) neutral redirection (Steele, 1995).

\section{Dependent Variables and Measures}

To obtain frequency counts on the three dependent variables, co-teaching models, student specific accommodations and modifications, and PBIS, we used direct and systematic observation of each dyad's co-planning and co-teaching sessions without (during baseline and withdrawal phases) and with the eCoaching intervention. As noted previously, we captured and electronically archived each session. We used the video files as the primary source for data collection across all conditions in all phases. More specifically, we recorded (via frequency counts) the varied types of Friend and Cook's (2003) co-teaching models each co-teaching dyad planned to use during instruction. Then, during the planned lessons, we recorded (via frequency counts) the co-teaching models the pairs actually carried out. We also documented the changes in the number and types of student-specific accommodations and modifications from baseline to treatment phases through frequency counts of accommodations co-planned and used during subsequent co-taught instruction. Finally, we used frequency counts to record the type and number of PBIS strategies (i.e., redirects, reprimands, and praise statements) each co-teaching dyad planned and used.

\section{Procedures}


Horner et al. (2005) recommended that single case researchers ensure the baseline condition is as similar to the intervention condition as possible. We met this standard by visiting classrooms during the same content area instruction and for equal amounts of time during each observation. All observations and coaching sessions were conducted via the eCoaching technology.

Baseline. During the baseline condition, the first author observed each participating pair of teachers as they cooperatively planned for and carried out instruction. The co-planning sessions took place in the general education classroom so that we were able to observe through the eCoaching system. The first author greeted the participants and recorded each 30-minute planning session for analysis, but did not provide immediate or delayed feedback to the participants at any time before, during, or after the planning sessions.

The first author then visited the classroom to observe 30 minutes of the planned co-taught lessons. Again, we recorded the lessons for analysis, but did not provide eCoaching feedback to the participants before, during, or after the lessons. To establish similar conditions during baseline and intervention, the participants alternated wearing the Bluetooth earpiece during cotaught instruction. This also allowed participants and their students to become familiar with the technology.

Intervention. Once baseline stability requirements were met (i.e., four data points, level trend, and little variability for at least one dependent variable), the first author introduced the eCoaching intervention. During the initial intervention phase, the first author coached (i.e., provided encouraging, corrective, questioning, and instructive feedback via the advanced online BIE) participants as they cooperatively planned a co-taught lesson.

After each 30-minute co-planning session, the first author visited each classroom for 30 minutes during the planned co-taught lesson. Throughout each lesson, the first author provided eCoaching (i.e., immediate feedback) to one co-teacher participant through the advanced online BIE system. eCoaching continued for four sessions (i.e., Planning-Teaching- Planning-Teaching) with each co-teaching dyad, then we withdrew the intervention and the withdrawal phase began (Gast, 2010; Kratochwill et al., 2010).

Withdrawal. During the withdrawal phase, we replicated the procedures used in the first baseline phase. Data collection during withdrawal continued for four observational sessions (i.e., Planning-Teaching-Planning-Teaching; Kratochwill et al., 2010).

Return to intervention. To reintroduce the eCoaching intervention, we replicated procedures used during the first intervention phase of the study. This final phase continued until stability in trend was established. As with the first intervention phase, we obtained a minimum of four data points for each co-teaching dyad as the adopted standard for the return to intervention phase (Kratochwill et al., 2010). After completing the return to intervention phase, the first author interviewed each participant to measure the social validity of the eCoaching intervention. 
As described previously, we recorded all sessions using Call Recorder for Mac (Ecamm Network, LLC, 2011). During each session, immediately after accepting the Skype call, Call Recorder prompts the participant to accept or decline the video recording. Also, at any time during a session, participants had the option of terminating the online connection by ending the Skype call.

Primary and secondary observers, individually and separately, coded the archived video files for each dependent variable. To do so, the observers extracted, recorded, and totaled counts using procedures mirroring those used during the baseline phase on data collection protocols adapted from Rock et al. (2009) and Rock et al. (2012). Next, the observers entered these data into an Excel spreadsheet at the end of each coding session. Finally, they regularly plotted these data onto a line graph, using the Microsoft Excel software.

\section{Data Analysis}

We assessed changes in each co-teaching dyad's co-planning and co-teaching behaviors between the baseline and intervention phases, using visual inspection (Tankersley, Harjusola- Webb, \& Landrum, 2008). To do so, we created graphic displays illustrating accelerating, decelerating, or variable trends in the number of co-teaching models planned and implemented (see Figures 1-4); number of student specific accommodations and modifications planned and implemented (see Figure 5); and number of redirections, and specific and descriptive praise statements (see Figure 6). These graphic displays can be seen in Figures 1 to 6 . The level or change in co-planning and co-teaching behavior immediately after implementation of the eCoaching intervention, and the latency or quickness of co-planning and co-teaching behavior change at the end of one condition and beginning of another (i.e., baseline or intervention) are also displayed in Figures 1 and 5 (Kazdin, 2011; Tankersley et al., 2008). Finally, we calculated and compared the mean number of each dyad's co-planning and co-teaching behaviors, during each phase, to establish the effect of the eCoaching intervention (Kazdin, 2011; Tankersley et al., 2008). See Table 2 for changes in means observed across the four phases of this study.

\section{Treatment Effect}

We calculated and analyzed treatment effect using the Percent of Non-Overlapping Data (PND) methods (Scruggs, Mastropieri, \& Castro, 1987). To do this, the number of data points in the first intervention phase that exceed the highest data point in the first baseline phase was divided by the total number of data points in the first intervention phase. The quotient was then multiplied by 100 , so that the resulting number became a percentage score (Scruggs \& Mastropieri, 1998). Identical methods were used to analyze the withdrawal phase and the return to intervention phase. Finally, we followed procedures outlined by Scruggs and Mastropieri for total PND (Scruggs \& Mastropieri, 1998, pp. 223-224). See Table 2 for the means, standard deviations, and PND of each dependent variable.

\section{Inter-Observer Agreement}


(IOA)

To establish IOA, we trained the two observers mentioned previously to code the archived video files. During training, they viewed The Power of Two, a commercially published videodisk (Friend, 2005) to ensure understanding of the co-teaching models examined in the study. Also, they reviewed data collection protocols, learned the operational definitions for each co-teaching behavior of interest, and practiced coding using excerpts from The Power of Two.

The first author served as the primary observer; she coded all of the recorded video files. The second observer was a retired elementary school teacher and college supervisor; she coded 25\% of all archived video files as the reliability observer. The primary and secondary observers had extensive experience (i.e., three years) coding video files using similar protocols on a federally funded personnel development grant.

In this study, we calculated IOA based on the following formula (see Kazdin, 2011): The number of agreement of codes divided by the number of agreement of codes + disagreement $\times 100$. Also, we relied on Barlow et al.'s (2009) guidelines (i.e., $80 \%=$ conventional and $90 \%$ agreement $=$ preferred) to establish $80 \%$ agreement as the minimum standard for IOA. When agreement fell below $80 \%$, the observers retrained in the coding procedures, operational definitions, and then recoded archived video files. In the end, $80 \%$ agreement was achieved on all dependent variables.

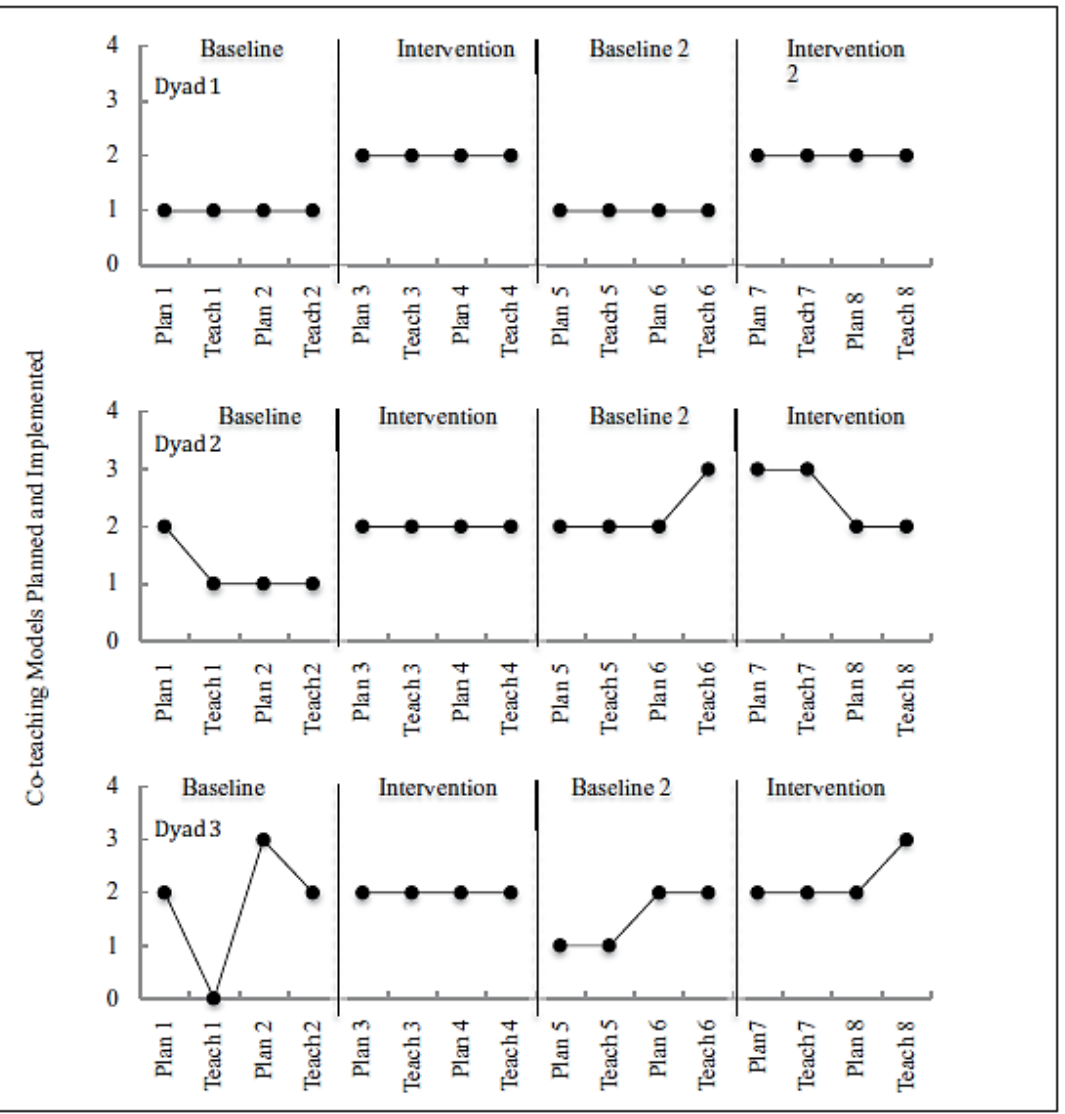


Figure 1. Frequency counts of co-teaching models planned and implemented.

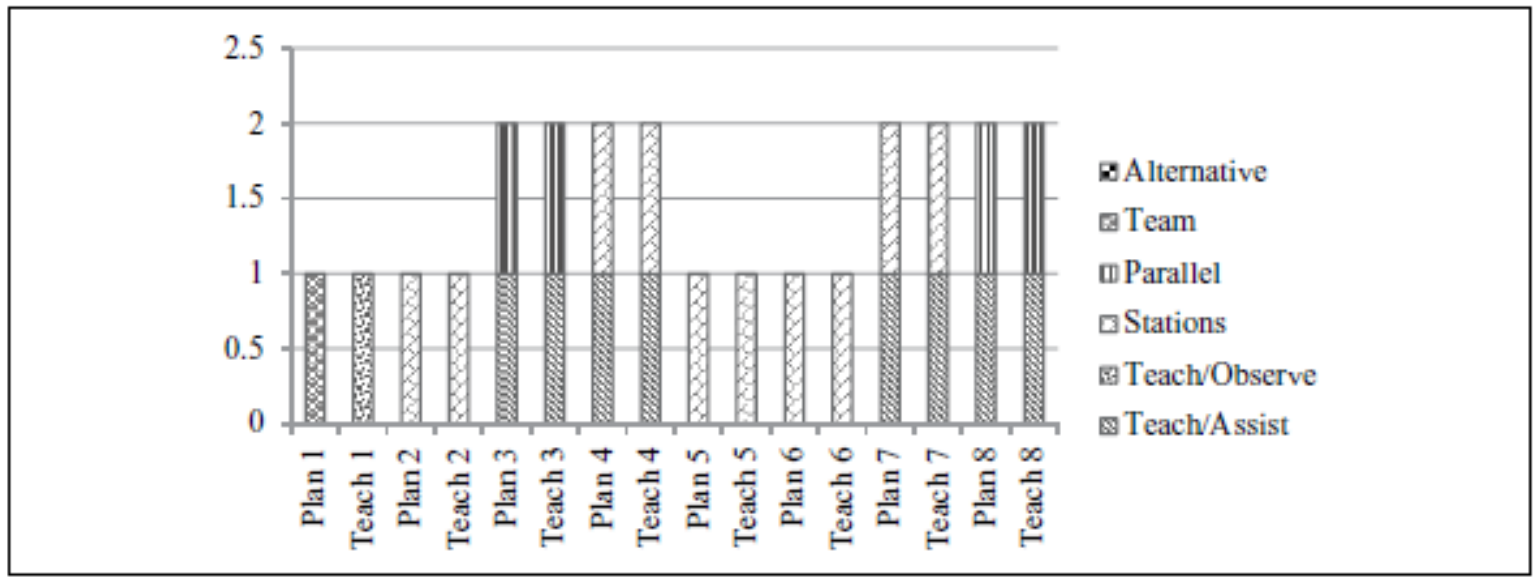

Figure 2. Dyad 1 varied co-teaching models planned and implemented.

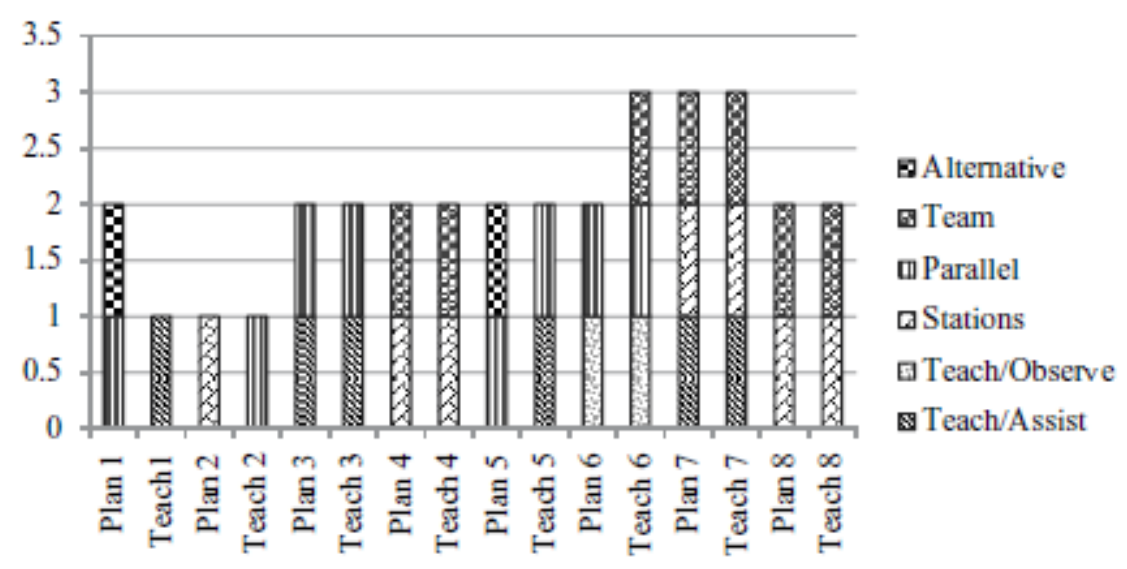

Figure 3. Dyad 2 varied co-teaching models planned and implemented.

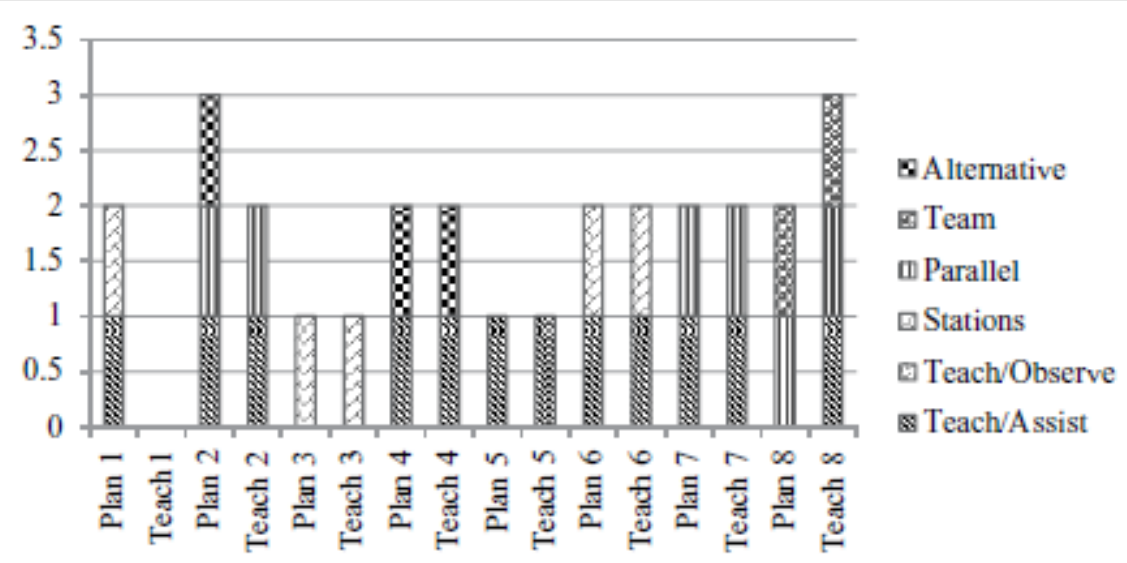

Figure 4. Dyad 3 varied co-teaching models planned and used. 


\section{Results}

\section{Co-Teaching Models Planned and Implemented}

Number of co-teaching models planned and implemented. All three dyads increased the number of varied co-teaching models they planned to use and then implemented (see Table 2 and Figure 1). Dyad 1 increased their varied models of co-teaching from an average of one model $(1,1,1$, and 1) during baseline to an average of two co-teaching models (2, 2, 2, and 2) during the final intervention phase. Dyad 1's PND was 100\% indicating a very effective intervention. Dyad 2 increased co-teaching models planned for and implemented from an average of 1.25 during baseline $(2,1,1$, and 1$)$ to $2.5(3,3,2$, and 2$)$ in the final phase. PND for Dyad 2 was $0 \%$ indicating the eCoaching intervention was not effective for Dyad 2. Dyad 3 increase the average number of co-teaching models they planned and implemented from an average of 1.75 (2, 0, 3, and 2) during baseline to an average of 2.5 co-teaching models (2, 2, 2, and 3) during the final intervention phase. PND for Dyad 3 was 13\% indicating the eCoaching intervention was ineffective.

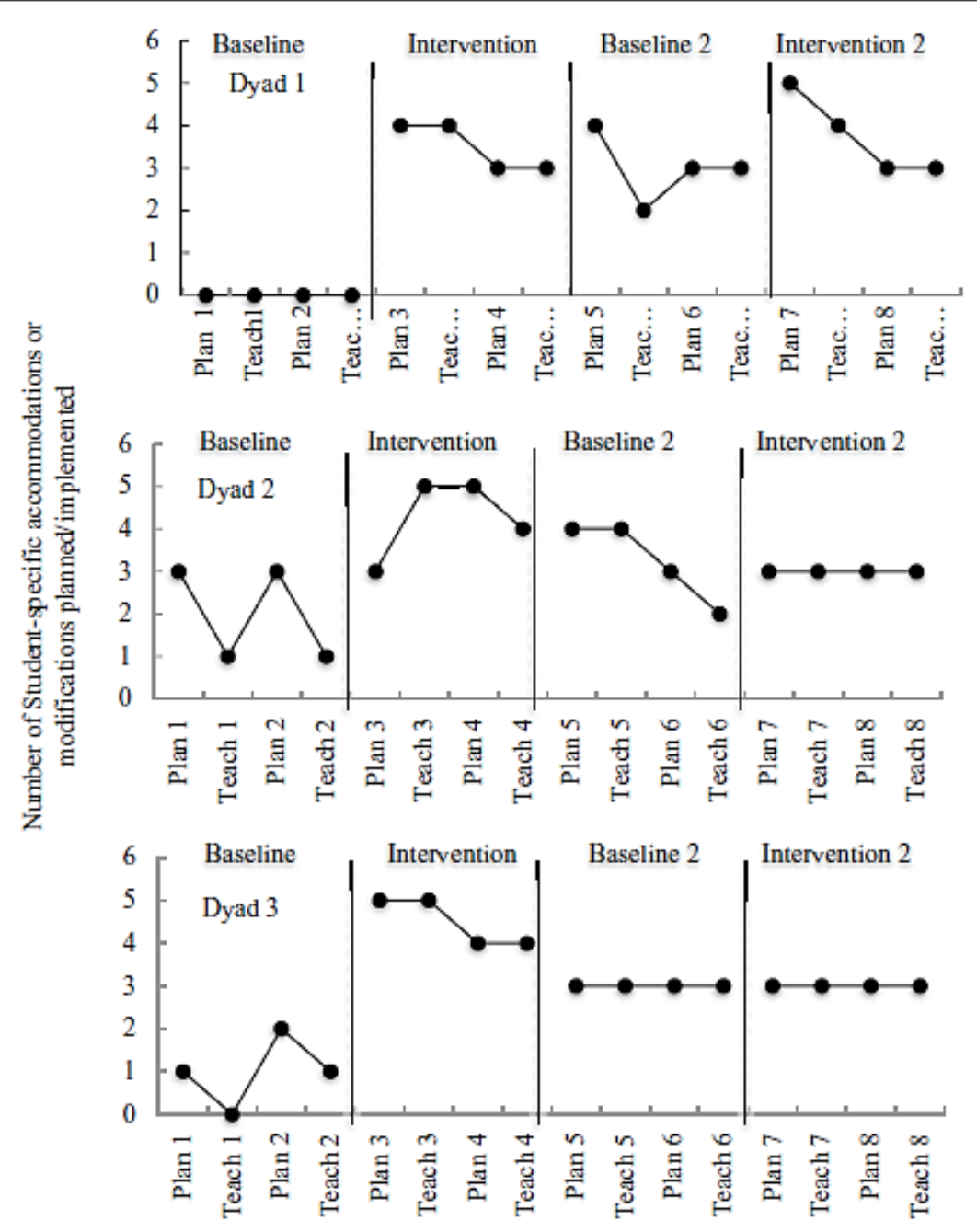


Figure 5. Student-specific accommodations or modifications planned/implemented.

Fidelity to planned co-teaching models. In addition to investigating the number of different coteaching models each dyad used, we were interested in exploring whether the dyads actually carried out the co-teaching models they planned (i.e., fidelity to planned co-teaching models). Over the course of this study, all three co-teaching dyads increased their fidelity to the varied coteaching models they planned. During baseline data collection, Dyad 1 planned to use the team teaching model, but they did not implement it. Instead, they carried out one teach, one observe for their first co-taught lesson. During the second two sessions of baseline data collection, Dyad 1 planned for station teaching and implemented it (see Figure 2). Dyad 1 implemented their planned co-teaching models in $50 \%$ of the baseline sessions. Dyad 2 planned to use alternative and parallel teaching, then implemented one teach, one assist. The next two baseline sessions included a plan for station teaching, but the implementation of parallel teaching (see Figure 3). Although Dyad 2 attempted to vary the number of co-teaching models planned and implemented during the first baseline phase, they did not follow through with the lessons as planned. Throughout the first baseline sessions, the dyad implemented $0 \%$ of the co-teaching models they had planned to use. Dyad 3 planned to use one teach, one assist and station teaching during their first co-teaching session; however, the special education teacher was not present. The teachers did not co-teach, instead the general education teacher used whole group instruction while she waited for the special educator. For the next two baseline sessions, Dyad 3 planned for alternative teaching; one teach, one assist; and parallel teaching, but implemented one teach, one assist and parallel teaching during the final two sessions of baseline data collection (see Figure 4). Dyad 3 implemented $40 \%$ of the co-teaching models that were planned during the first baseline phase of the study. 


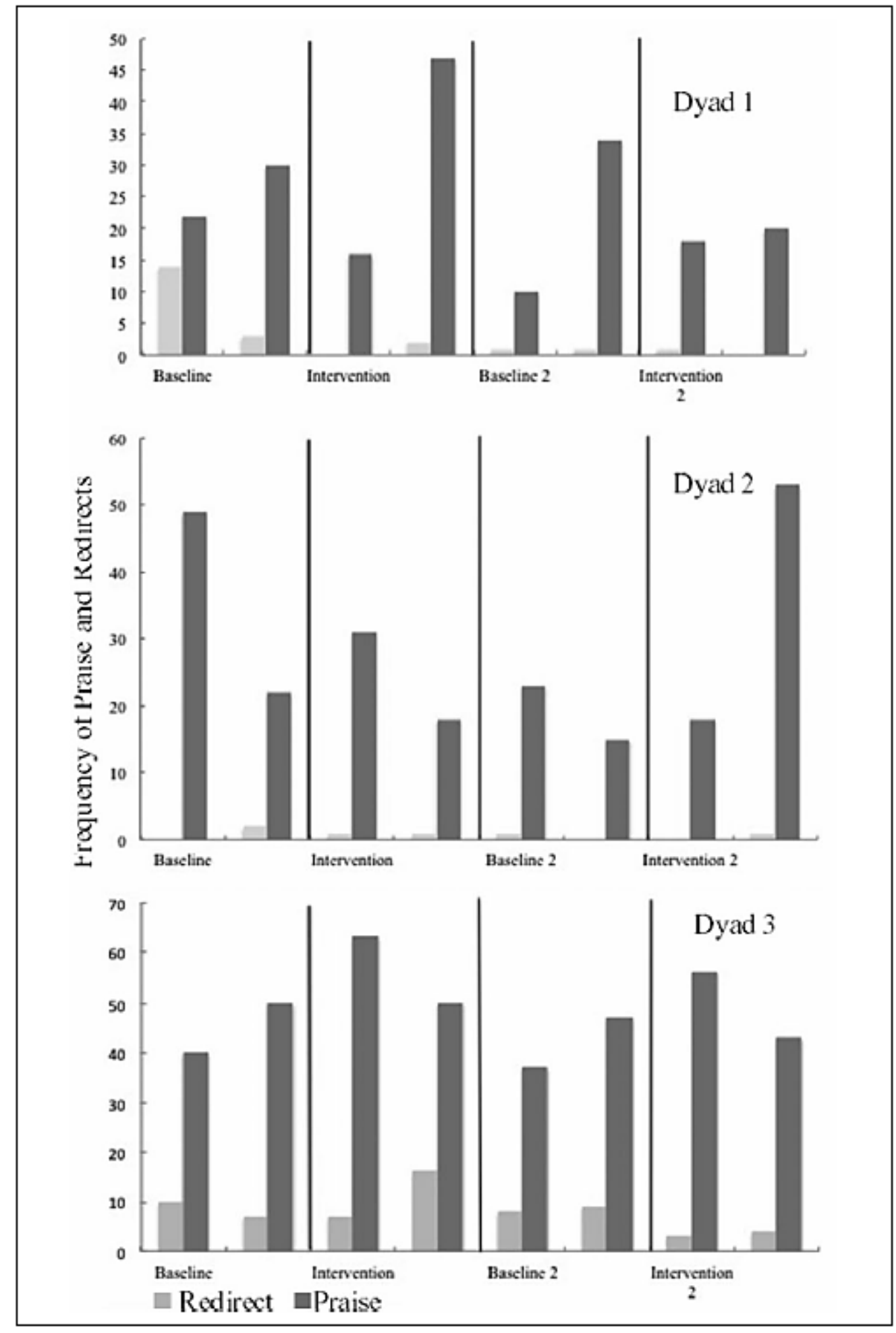

Figure 6. Frequency counts of redirection and specific, descriptive praise.

Table 2. Means, Standard Deviations, and Percentages of Non-Overlapping Data for Participants Across Phases. 


\begin{tabular}{|c|c|c|c|c|c|c|c|c|}
\hline \multirow[b]{3}{*}{ Participant/phase } & \multirow{2}{*}{\multicolumn{2}{|c|}{$\begin{array}{l}\text { Co-teaching } \\
\text { models }\end{array}$}} & \multicolumn{6}{|c|}{ Positive behavioral interventions and supports } \\
\hline & & & \multicolumn{2}{|c|}{$\begin{array}{l}\text { Accommodations or } \\
\text { modifications }\end{array}$} & \multicolumn{2}{|c|}{ Redirections } & \multicolumn{2}{|c|}{ Praise } \\
\hline & $M$ & SD & $M$ & $S D$ & $M$ & $S D$ & $M$ & SD \\
\hline \multicolumn{9}{|l|}{ Dyad 1} \\
\hline Baseline & 1.00 & 0.00 & 0.00 & 0.00 & 8.50 & 7.78 & 25.00 & 5.66 \\
\hline Intervention & 2.00 & 0.00 & 3.50 & 0.58 & 1.00 & 0.00 & 31.5 & 21.92 \\
\hline PND & 100 & & 100 & & & & & \\
\hline Baseline 2 & 1.00 & 0.00 & 3.00 & 0.82 & 1.00 & 0.00 & 22.00 & 16.97 \\
\hline Intervention 2 & 2.00 & 0.00 & 3.75 & 0.96 & 0.50 & 0.71 & 19.00 & 1.41 \\
\hline PND 2 & 100 & & 25 & & & & & \\
\hline Total PND & 100 & & 63 & & & & & \\
\hline \multicolumn{9}{|l|}{ Dyad 2} \\
\hline Baseline & 1.25 & 0.50 & 2.00 & 1.15 & 1.00 & 1.41 & 30.50 & 26.16 \\
\hline Intervention & 2.00 & 0.00 & 4.25 & 0.96 & 1.00 & 0.00 & 24.50 & 9.19 \\
\hline PND & 0 & & 75 & & & & & \\
\hline Baseline 2 & 2.25 & 0.50 & 4.33 & 0.96 & 0.50 & 0.71 & 19.00 & 5.66 \\
\hline Intervention 2 & 2.50 & 0.58 & 3.00 & 0.00 & 0.50 & 0.71 & 27.50 & 13.44 \\
\hline PND 2 & 0 & & 0 & & & & & \\
\hline Total PND & 0 & & 38 & & & & & \\
\hline \multicolumn{9}{|l|}{ Dyad 3} \\
\hline Baseline & 1.75 & 1.26 & 1.00 & 0.82 & 8.50 & 2.12 & 45 & 7.07 \\
\hline Intervention & 2.00 & 0.00 & 4.00 & 0.58 & 11.50 & 6.36 & 56.50 & 9.19 \\
\hline PND & 0 & & 100 & & & & & \\
\hline Baseline 2 & 1.50 & 0.58 & 3.00 & 0.00 & 8.50 & 0.71 & 42.00 & 7.07 \\
\hline Intervention 2 & 2.50 & 0.50 & 3.00 & 0.00 & 3.5 & 0.71 & 49.50 & 9.19 \\
\hline PND 2 & 25 & & 0 & & & & & \\
\hline Total PND & 13 & & 50 & & & & & \\
\hline \multicolumn{9}{|l|}{ Means } \\
\hline Baseline & 1.33 & 0.78 & 1 & 1.13 & 6.00 & 5.33 & 33.5 & 15.24 \\
\hline Intervention & 1.92 & 0.00 & 4 & 0.79 & 4.50 & 6.16 & 33.6 & 18.88 \\
\hline PND & 33 & & 92 & & & & & \\
\hline Baseline 2 & 1.60 & 0.67 & 3.44 & 0.67 & 3.30 & 4.03 & 27.70 & 14.11 \\
\hline Intervention 2 & 2.25 & 0.45 & 3.25 & 0.62 & 1.50 & 1.64 & 32.00 & 15.86 \\
\hline PND 2 & 42 & & 8 & & & & & \\
\hline Total PND & 38 & & 50 & & & & & \\
\hline
\end{tabular}

Note. PND = percentage of non-overlapping data. PND and PND 2 scores were summed to produce total PND (Scruggs \& Mastropieri, 1998, pp. 223-224).

During the first intervention phase, eCoaching was introduced during planning and instruction for four teaching and planning sessions. During the first planning session, Dyad 1 planned to use one teach, one assist and parallel teaching for the lesson that followed planning. The lesson was carried out as planned. The next two coached sessions in the phase continued with the coteachers planning to implement one teach, one assist as the lesson introduction and station 
teaching as the lesson body. During the fourth session, of the first intervention phase (Phase 2), the co-teachers implemented the planned co-teaching models with fidelity to their plan (see Figure 2). Throughout this eCoaching intervention phase, co-teaching Dyad 1 implemented $100 \%$ of the co-teaching models they planned for each session. Dyad 2 began the first eCoaching phase of the study with a plan for one teach, one assist during the introduction of the lesson and the parallel teaching model for the remainder of the lesson. The lesson was implemented as planned. During the next eCoached planning session, Dyad 2 planned to use of the team teaching model as the lesson introduction and station teaching as the lesson body. The pair again implemented the lesson according to the planned models of co-teaching (see Figure 3).

Once eCoaching was introduced, the number of co-teaching models leveled out at two. Moreover, in $100 \%$ of the cases co-teaching models were implemented as planned. Dyad 3 planned and implemented station teaching during the first two eCoached sessions. The final two sessions of the eCoaching intervention phase included co-planned use of one teach, one assist and alternative teaching. The lesson was implemented with fidelity to the planned co-teaching models (see Figure 4). The introduction of eCoaching intervention contributed to an increase to $100 \%$ implementation of co-teaching models the dyad planned during the first intervention phase.

When eCoaching was withdrawn, Dyad 1 planned and used the station teaching model during all four sessions (see Figure 2). The dyad continued to implement $100 \%$ of the co-teaching models that they planned. Dyad 2 planned to carry out alternative teaching and parallel teaching during one of the four sessions, but implemented one teach, one assist in place of the alternative teaching model when the lesson followed. During the next two sessions, the dyad planned for one teach, one observe and parallel teaching. They used each model during the lesson and added team teaching to the lesson introduction (see Figure 3). When the eCoaching intervention was withdrawn, Dyad 2 implemented 59\% of the co-teaching models they planned for the sessions. Dyad 3 planned for and implemented one teach, one assist during the first two sessions of return to baseline. The co-teaching partners then planned and implemented a combination of one teach, one assist and station teaching during the next two planning and teaching sessions (see Figure 4). When the eCoaching intervention was withdrawn, Dyad 3 returned to planning for one coteaching model and then implemented that co-teaching model in $100 \%$ of the teaching sessions.

The final phase of the study reintroduced eCoaching to the co-teaching dyads, during planning and teaching sessions. In the final phase, Dyad 1 planned for and implemented one teach, one assist and station teaching and then one teach, one assist and parallel teaching with fidelity to all planned co-teaching models (see Figure 2). In the final phase of the study, Dyad 1 returned to two co-teaching models for planning and implementation. The dyad implemented $100 \%$ of the planned co-teaching models. Overall, Dyad 1 implemented four of the six possible co-teaching models. The dyad implemented the co-teaching models they had planned for in $88 \%$ of their coteaching sessions. Dyad 2 planned for and implemented one teach, one assist, team teaching, and station teaching during the first two sessions of the final eCoaching phase. During the last two 
sessions, the duo planned for and carried out team teaching combined with station teaching (see Figure 3). In the final phase of the study, the co-teachers implemented $100 \%$ of the co-teaching models planned. Overall, this dyad implemented five of the six possible co-teaching models. Dyad 2 implemented the co-teaching models they planned 65\% of the time. Dyad 3 planned for and implemented one teach, one assist and parallel teaching during the first two sessions of this eCoaching phase. During the final two sessions, the co-teaching pair planned for the combination of team teaching and parallel teaching, when the lesson followed the pair added one teach, one assist to the combination of co-teaching models (see Figure 4). In the final phase of the study, Dyad 3 implemented 100\% of the planned models and added a third model to the final lesson that was not planned. Overall, Dyad 3 planned and implemented five of the six possible coteaching models. Dyad 3 implemented the co-teaching models they planned for in $76 \%$ of their co-teaching sessions.

\section{Student-Specific Accommodations or Modifications}

All three co-teaching dyads increased the number of student-specific accommodations planned and implemented from baseline to the final phase of the study (see Figure 5). During Baseline, Dyad 1 averaged zero student specific accommodations planned and implemented $(0,0,0$, and 0 ). Dyad 1 increased the number of student-specific accommodations they planned and implemented during instruction to an average of 3.75 (5, 4, 3, and 3) during the final eCoaching intervention phase. Dyad 2 increased their average number of student-specific accommodations planned and implemented from two $(3,1,3$, and 1$)$ at baseline to three $(3,3,3$, and 3$)$ during the final eCoaching intervention phase. Dyad 3 increased the average number of student-specific accommodations planned and implemented from one $(1,0,2$, and 1$)$ at baseline to three $(3,3,3$, and 3 ) in the final eCoaching intervention phase of the study.

During the first two baseline and intervention phases, the PND for Dyad 1 was 100\%. This score indicated that the eCoaching intervention was highly effective. PND for Dyad 2 was 75\% for the first two phases of the study. The score indicated that the eCoaching intervention was effective. The PND for Dyad 3 was 100\% during the preliminary baseline and eCoaching intervention phases, which indicated the eCoaching intervention was highly effective during the two initial phases. When PND was combined for all three co-teaching dyads, overall PND for the first baseline and eCoaching intervention phases was 92\%, which indicated that the eCoaching intervention was highly effective for changing co-teachers planning and implementation of student-specific accommodations or modifications.

When the eCoaching intervention was withdrawn and then reintroduced, the PND for Dyad 1 decreased to $25 \%$. This percentage score indicated that the eCoaching intervention was ineffective during the final two phases. The total PND for Dyad 1 was 63\%, which indicated a questionable total effect. During the withdrawal and reintroduction of the eCoaching intervention, Dyad 2 accumulated a PND of $0 \%$. This score indicated that the eCoaching intervention was ineffective during the final two phases. This provided a total PND of 38\%, 
which indicated the eCoaching intervention was ineffective through all phases. For Dyad 3, PND decreased to $0 \%$ for the final two phases of the study. This percentage score indicated that the eCoaching intervention was ineffective during the final two phases. The total PND for all phases of the investigation for Dyad 3 was 50\%. This total PND indicated that the eCoaching intervention's effect was questionable. When PND was combined for all three dyads during the withdrawal and reintroduction of the eCoaching intervention, the PND was $8 \%$. This percentage indicated that the eCoaching intervention was ineffective during the final two phases. Combined PND for all three co-teaching dyads throughout all phases of the investigation was $50 \%$. This combined PND score indicated the eCoaching intervention's effect was questionable.

\section{PBIS}

Table 2 includes mean numeric scores for use of PBIS through redirections and specific, descriptive praise statements. Figure 6 reflects each co-teaching dyad's individual data for number of redirections and student-specific praise during co-teaching instruction. The bar graphs included in this figure do not include planning data because the co-teaching dyads either planned to use PBIS or did not plan for PBIS. In other words, they did not identify a targeted number of praise or redirection statements they wished to use. Consequently, it was not appropriate to compare PBIS co-planning data (i.e., yes or no) with PBIS co-teaching data (i.e., frequency counts).

Redirection. All three co-teaching dyads decreased the average number of redirections from baseline to the final intervention phase. During the first baseline phase, Dyad 1 did not plan PBIS and averaged eight and one half (14 and 3) redirections. Dyad 2 planned for PBIS and averaged one ( 0 and 2 ) redirection during baseline. Dyad 3 did not plan for PBIS and averaged 8.5 (3 and 10) redirections during baseline.

During the first intervention phase, Dyad 1 planned for PBIS and averaged 1 (0 and 2) redirection. During the first intervention phase, Dyad 2 continued to plan PBIS and averaged 1 (1 and 1) redirection during the eCoaching intervention. During the first eCoaching intervention phase, Dyad 3 did not plan for PBIS and averaged 11.5 (7 and 16) redirections during the eCoaching intervention.

When eCoaching was withdrawn, Dyad 1 continued to plan for PBIS and averaged 1 (1 and 1) redirection for each lesson. During the withdrawal of the eCoaching intervention, Dyad 2 continued to plan for PBIS and averaged 0.5 (1 and 0 ) of a redirection a lesson. During the withdrawal of the eCoaching intervention, Dyad 3 did not plan for PBIS and averaged 8.5 (8 and 9) redirections a lesson.

Once the eCoaching intervention was reintroduced, Dyad 1 continued to plan for PBIS and averaged 0.5 (1 and 0) of a redirection per lesson. When the eCoaching was reintroduced, Dyad 2 continued to plan for PBIS and maintained a low average of 0.5 ( 0 and 1 ) of a redirection per 
lesson. During this eCoaching intervention phase, Dyad 3 planned for PBIS and decreased their average of redirections for each lesson to 3.5 (3 and 4).

Specific, descriptive praise. Throughout all phases of the investigation, each co-teaching dyad maintained at least a four to one ratio of specific, descriptive praise to redirections with the exception of Dyad 1 during the first baseline phase (see Figure 6). Dyad 1 did not plan for PBIS and praised students an average of 25 (22 and 30) times during baseline lessons. Dyad 2 planned for PBIS and averaged 30.5 (49 and 12) specific, descriptive praise statements during baseline. Dyad 3 praised students more than the other two dyads. Dyad 3 did not plan for PBIS yet averaged 45 (40 and 50) specific, descriptive praise statements during baseline.

During the first intervention phase, Dyad 1 planned for PBIS and gave specific, descriptive praise an average of 31.5 (16 and 47) times in each 30-minute lesson. Throughout the first intervention phase, Dyad 2 planned for PBIS and averaged 24.5 (31 and 18) specific, descriptive praises for each 30-minute lesson. Dyad 3 did not plan for yet averaged 56.5 (50 and 63) specific, descriptive praise statements during each 30-minute lesson in the first intervention phase.

When the eCoaching intervention was withdrawn, Dyad 1 continued to plan for PBIS and averaged 22 (10 and 34) specific, descriptive praise statements for each 30-minute lesson. During the eCoaching intervention withdrawal, Dyad 2 continued to plan PBIS. This dyad averaged 19 (23 and 15) specific, descriptive praise statements during each 30-minute lesson. When the researcher withdrew the eCoaching from Dyad 3, the dyad continued not to plan for PBIS and averaged 42 (37 and 47) specific, descriptive praise statements during the two 30minute lessons in the withdrawal phase.

Upon reintroduction of eCoaching, Dyad 1 planned for PBIS and averaged 19 (18 and 20) specific, descriptive praise statements during each 30-minute lesson. Once eCoaching resumed for Dyad 2, they averaged 35.5 (18 and 53) specific, descriptive praise statements per 30-minute lesson. During this eCoaching intervention phase, Dyad 3 planned for PBIS and averaged 49.5 (56 and 43) specific, descriptive praise statements during each 30-minute co-taught lesson.

The average number of specific descriptive praise by all three co-teaching dyads remained consistent at 33.5 and 33.6 during the first baseline and intervention phases respectively. The average number of specific, descriptive praises during withdrawal decreased to 27.7 statements. In the final phase, the three dyads averaged 32 specific, descriptive praise statements for each 30-minute lesson (see Table 2 and Figure 6).

Table 3. Percent Student Engagement Throughout Each Study Phase.

\begin{tabular}{|l|c|c|l|l|l|l|l|l|l|l|}
\hline & \multicolumn{2}{|c|}{ Baseline } & \multicolumn{2}{l|}{ Intervention } & \multicolumn{2}{l|}{ Baseline 2 } & \multicolumn{2}{l|}{ Intervention 2 } & \multicolumn{2}{c|}{ Overall } \\
\hline Classroom & \% & SD & \% & SD & \% & SD & \% & SD & \% & SD \\
\hline Dyad 1 & 95 & 7.6 & 96 & 5.6 & 98 & 2.3 & 99 & 2.1 & 97 & 4.1 \\
\hline
\end{tabular}




\begin{tabular}{|l|l|l|l|l|l|l|l|l|l|l|}
\hline Dyad 2 & 98 & 2.2 & 100 & 0.0 & 100 & 0.0 & 100 & 0.0 & 100 & 1.1 \\
\hline Dyad 3 & 95 & 4.2 & 95 & 6.5 & 91 & 10.6 & 99 & 1.6 & 95 & 5.9 \\
\hline Combined & 96 & 4.4 & 97 & 4.4 & 96 & 6.5 & 99 & 1.4 & 97 & 4.4 \\
\hline
\end{tabular}

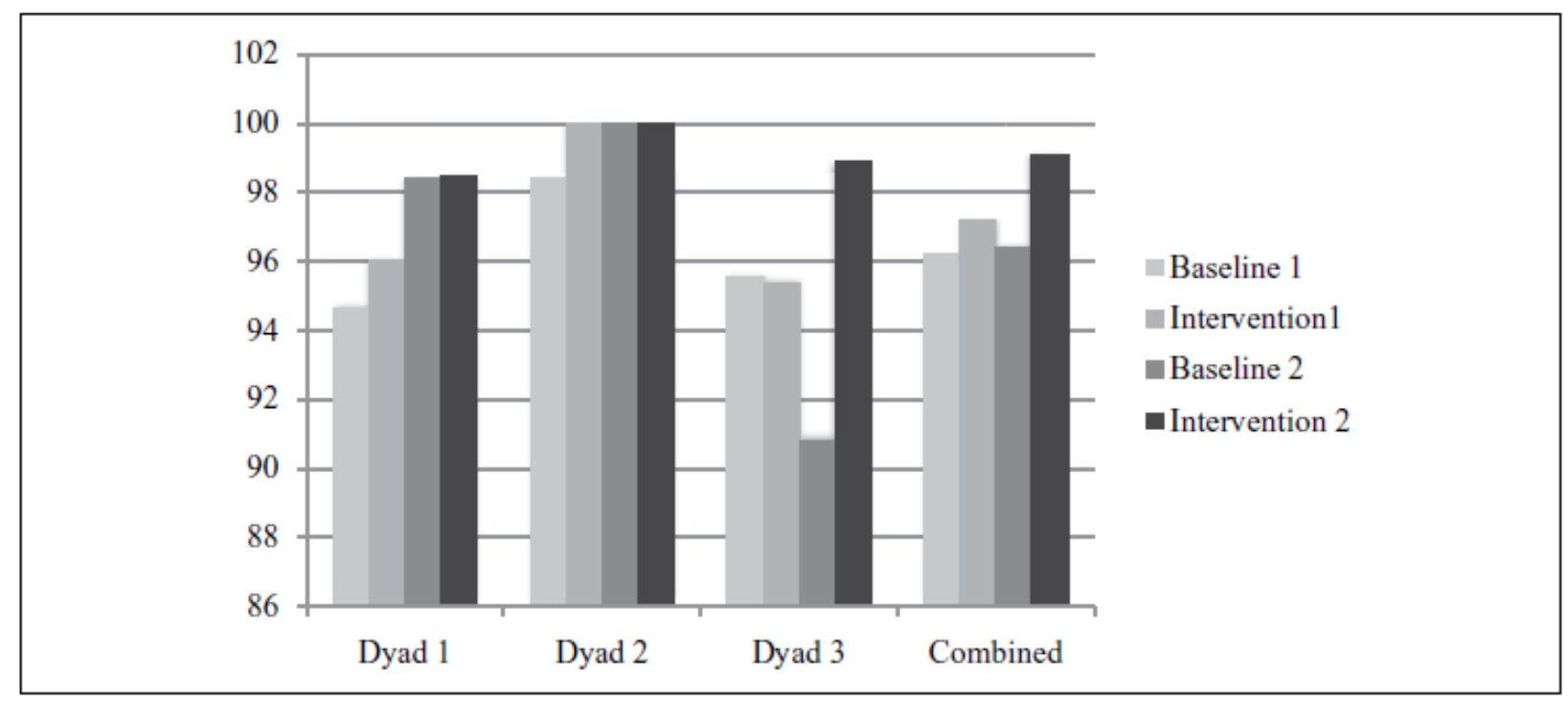

Figure 7. Percent of students’ academic engagement/on-task behavior.

\section{Treatment Integrity (Fidelity to eCoaching)}

We measured treatment integrity via frequency counts of the type of eCoaching statements used by extracting the eCoach's comments from the archived video files and recording whether the statements made were encouraging, questioning, or instructional. Next, we entered total values for each category into an Excel document for further analysis. Then, we calculated percent agreement for frequency of statements for each co-teaching dyad individually and all three coteaching dyads combined (i.e., Dyad $1=99 \%$, Dyad $2=99 \%$, Dyad $3=94 \%$, and combined = $97 \%)$. Also we calculated the ratio of encouraging to corrective feedback and compared it with the recommended level of 4:1 (Alberto \& Troutman, 2003). In all three cases, the eCoach met the suggested ratio of encouraging to corrective feedback: Dyad 1 ratio $=4.91: 1$, Dyad 2 ratio $=$ 13:1, Dyad 3 ratio $=11.47: 1$, and Overall $=7.63: 1$.

\section{Social Validity}

To measure social validity, we investigated the impact (i.e., disruption and benefit) of eCoaching on co-teachers and their students in two ways: (a) P-6 student engagement during co-taught lessons and (b) co-teachers' perceptions of eCoaching.

Student engagement. Our first measure of social validity included momentary time sampling techniques to determine the percent of student engagement throughout each co-taught lessons. We used this measure to investigate whether changes in the instructional format and the 
eCoaching condition affected the percentage of students who were academically engaged throughout each lesson. To do so, we used five minute intervals to code student engagement during each 30-minute lesson (Rock et al., 2009). Mean percentages of students who were academically engaged (i.e., defined as on task) increased for each of the co-teaching dyads (see Table 3 or Figure 7). For Dyads 1 and 2, the mean percent of increased student engagement did not return to the initial baseline percentage. For Dyad 3, percent engagement remained the same from baseline to intervention, and then decreased when the eCoaching intervention was withdrawn. In the final intervention phase, Dyad 3 had the highest increase in student engagement.

Co-teacher interviews. The second measure of social validity was based on interviews with participants. After completing the final phase of this study, all six participants agreed to brief interviews. The interviews we conducted with participating co-teaching pairs were adapted from questions used by Scheeler et al. in 2010. All respondents indicated that the eCoaching experience was beneficial for coteachers and their K-5 students. Eighty percent of co-teachers stated that they enjoyed the experience greatly while the other $20 \%$ indicated benefits of the eCoaching while planning but found the eCoaching during instruction distracting during early sessions. All co-teachers (100\%) stated that the eCoaching during co-planning was beneficial.

Was the eCoaching helpful in preparing for and teaching with your co-teacher? One participant specifically spoke of the benefit eCoaching provided in her transition into a new position and the implementation of co-teaching in the school. The co-teacher commented that the feedback provided during planning that linked engagement and the ability to reach all students was invaluable in assisting her to communicate the needs of students to her general education coteaching partner. Five co-teachers also reported that the eCoaching intervention assisted them to develop varied instructional methods/co-teaching models to reach all students in the general education classroom.

One of the essential components of a collaborative classroom is planning. Our eCoaching experience allowed us to share our ideas and voice them to with our coach. Often times when planning lessons, there may be gaps that may exist that one might not see. Our coach served as an extra pair of eyes to share ideas and make suggestions or corrections to our plans with the ultimate goal in mind and that is to increase student achievement and to include all students at all levels and behaviors.

I feel that the coaching sessions were significant in helping my co-teacher and I [sic] organize lesson plans that were well rounded, diverse, and suitable for all learners within the general education classroom.

Planning lessons in a classroom that I did not have full control of the students, instructional practices, procedures, and discipline, eCoaching helped me to consider details I may have taken for granted. 
The feedback was great food for thought as far as ideas and expanding them to give students the accommodations and help, they need to be successful.

The feedback provided us with ways to give students a better chance to be successful with more ideas and up to date accommodations and teaching practice.

What are some of the examples of feedback you found useful throughout the eCoaching sessions?

It was helpful getting advice on each lesson ahead of time rather than after the fact.

The suggestion to use a shared delivery of instruction was very beneficial. The suggestion was incredibly beneficial when we taught subtraction with regrouping. The students were exposed to the method of squaring off to subtract which I delivered. The students had an opportunity to see the co-teacher's method of subtracting by using standard regrouping. Now, all students are fluent in the use of both methods. Multiple representations of a skill were helpful and supported the practice of the Universal Design of Instruction.

What impact if any did this experience have on your students? Although there are no academic data to support achievement gains, all co-teachers stated they thought the eCoaching intervention positively impacted student achievement in their classrooms. One co-teaching dyad reported that pretest/posttest data indicated gain scores of two letter grades for students in the classroom when co-teaching was implemented through the study. Two other co-teachers reported students were impacted in positive ways because there was more teaching going on in the classroom. Four participants stated students were more engaged with small group activities when more than one teacher was present in the classroom. Two participants indicated achievement in their classrooms was improved, as students were eager to learn because the teaching methods provided fun and engaging activities that were different from the rest of the day.

Would you recommend the use of eCoaching to other professionals who are beginning the practice of co-teaching? Why or why not? Overall, all participants recommended the use of eCoaching for professionals who are beginning the practice of co-teaching.

\section{Discussion}

In this study, we systematically investigated the effects of eCoaching on co-teachers' planning sessions, as well as during their co-taught lessons. Our findings provide preliminary evidence for use of eCoaching, through advanced online BIE, with beginning co-teachers, and support the findings of previous researchers (i.e., Rock et al., 2012; Rock et al., 2009; Scheeler et al., 2010). The results of this study are promising given the limited time available for eCoaching and small sample size. Results from multiple measures of social validity confirm co-teachers found eCoaching not only feasible but also beneficial.

Co-Teaching Models 
Our review of co-teaching literature confirmed an over reliance on the one teach, one assist model of co-teaching (see Dieker, 2001; Harbort et al., 2007; Keefe \& Moore, 2004; Magiera, Smith, Zigmond, \& Gerbauer, 2005; Morocco \& Aguilar, 2002; Rice \& Zigmond, 2000; Scruggs et al., 2007; Weiss \& Lloyd, 2002) when teachers were left to implement co-teaching without guidance. In this study, the results for increasing the number of models in practice for each lesson were mixed. For co-teaching Dyad 1, eCoaching was highly effective in increasing the number of models put into practice. Yet, for Dyads 2 and 3, the eCoaching intervention was ineffective in increasing the number of models teachers used in each lesson. This may be due to a ceiling effect (Kazdin, 2011) because each lesson was limited to 30 minutes. The participants were aware that this was a co-teaching study and may have planned for and implemented more co-teaching models simply because they knew that the researcher was investigating co-teaching.

While the number of co-teaching models for each lesson was not affected in two of the coteaching dyads, fidelity to the variety of models each co-teaching dyad planned and used was increased by the eCoaching intervention. Our results support previous co-teaching research related to treatment integrity (B. G. Cook, McDuffie-Landrum, Oshita, \& Cothren Cook, 2011; Murawski \& Swanson, 2001; Rea, McLaughlin, \& Walther-Thomas, 2002; Weiss \& Lloyd, 2002). Classroom observations recorded and coded during baseline data collection indicated a lack of varied co-teaching practice. Likewise, Dieker (2001) reported that only one of nine coteaching teams observed used a variety of co-teaching models. In the Dieker (2001) study, four teams used one teach, one assist as their primary model of instruction while four teams used a teaming approach but only if they had appropriate planning time. Murawski and Swanson (2001) found that the researchers who completed the studies they analyzed were not clear about whether the co-teachers were implementing co-teaching as planned.

Similar to the results reported by Keefe and Moore (2004), without guidance in the implementation of co-teaching models, participants in this study did not implement the models of co-teaching that they had planned to use. Instead, they either settled into a division of labor where the general education teacher delivered instruction while the special education teacher assisted and supported individual students or they planned for one model of instruction and then carried out a different model (i.e., planned for station teaching and then used parallel for the lesson). Once eCoaching was introduced and participants were given clarification and guidance relevant to each model, instructional pace, and goals for model selection, co-teachers began planning and carrying out more varied co-teaching models. According to other researchers (Magiera \& Zigmond, 2005; Walther-Thomas, Korinek, McLaughlin, \& Williams, 2000), a wider range of co-teaching practices should be present when co-teaching is implemented within general education classrooms. In this study, while all three co-teaching dyads continued to use one teach one assist as part of the lesson cycle, they increased use of varied co-teaching models throughout their lessons when supported by the eCoaching intervention.

Accommodations and Modifications 
The specially designed instruction Zigmond and Baker (1995) reported missing in co-teaching practice was absent during the baseline (Phase 1) observational sessions in this study. As previous researchers found (Baker \& Zigmond, 1995; Magiera \& Zigmond, 2005; Zigmond \& Baker, 1995), although general education practices were implemented during the baseline phase of the study, few to no accommodations were carried out for students with identified disabilities. Indeed, Magiera and Zigmond noted a lack of effective instructional grouping and assistance, which they attributed to insufficient training. When prompted or queried through the eCoaching intervention, all three co-teaching dyads regularly planned for and supported students with appropriate accommodations based on individual student's Individualized Education Programs (IEPs). In 1995, Baker and Zigmond reported that the co-teachers in their study placed more emphasis on activities in the classroom than on specialized, personalized instruction for students with disabilities. The teachers who participated in this study centered discussions during baseline planning sessions largely on what to teach (i.e., looking through the teacher's manual) in the lesson, rather than how to teach the lesson or how to accommodate learning for individuals during the lesson. PND calculations for changes in co-teachers' use of student-specific accommodations or modifications confirmed the eCoaching intervention was highly effective for Dyads 1 and 3. The intervention was effective for Dyad 2. Although Dyad 2 had a lower PND score, they responded to the eCoaching intervention specific to students' needs. This dyad planned for and implemented general accommodations during the first baseline condition; when prompted by the coach to think of individual students' needs, these co-teachers provided individual students intensive instruction focused to meet his/her IEP goals. Kazdin (2011) stated that mixed results are often common in single case research as not everyone responds to treatments in the same way, even those that are well known to be effective (i.e., the use of aspirin for headache).

\section{PBIS}

As reported by Mastropieri et al. (2005), the classroom management type and approach general education teachers take may be different than those of the special education teacher. In addition, managing whole-class student behavior can be a problem for special educators who are used to working with individual students (Sindelar et al., 2010). In this study, when co-teaching dyads purposefully planned approaches to PBIS during planning sessions even if they spoke only of general guidelines within the classroom, they praised students frequently and had to redirect students' behaviors less often. As reported by Mastropieri et al. (2005), when both co-teachers employed effective motivational strategies (i.e., specific, descriptive praise and neutral redirection), co-teaching approaches appeared successful.

\section{Implications for Practice}

The results of this study have implications for co-teaching practice. First, if co-teaching is going to be the primary service delivery method to meet needs of students in inclusive general education classrooms (Cook et al., 2011; Magiera \& Zigmond, 2005; Volonino \& Zigmond, 
2007), then co-teachers must be provided with the support and training needed to carry out effective co-teaching. Quantitative data collected in this study supported the use of eCoaching to motivate co-teachers to plan for and transfer their knowledge of varied co-teaching models into classroom practice to provide effective co-teaching practice with fidelity. Second, when previous researchers (i.e., Dieker, 2001; Magiera \& Zigmond, 2005; Zigmond, 2001) investigated what happened to the special in special education, they found that nothing special was happening in the classrooms they observed. In this study, co-teachers provided students with specific accommodations when supported with the eCoaching intervention. Teachers had the knowledge of the instructional supports (i.e., accommodations or modifications) students needed, yet, without the support of the eCoach, either did not see the relevance for them in relation to what they were teaching or were not able to transfer or apply this knowledge into the general education setting. This transfer of knowledge is vital to the success of students with disabilities because they spend the majority of their day in the general education classroom (U.S. Department of Education, 2008). Therefore, co-teachers must be supported in situ through eCoaching or other job embedded approaches to maximize transfer of core special education principles (i.e., flexibility; intensive, individualized instruction in small groups; progress monitoring; assessment; use of evidence-based practices [Cook et al., 2010]) in the general education classroom.

\section{Limitations}

There are several limitations associated with this study that could not be controlled by the researcher. One was participants’ willingness to respond truthfully to the semi-structured interviews used to determine social validity (Gall, Gall, \& Borg, 2007). The fact that participants were "eager to participate" may call into question a contaminated sample. In addition, since the researcher was present during planning for and carrying out of various co-teaching lessons, the Hawthorne effect (i.e., participants change in typical behavior merely because of the presence of the researcher) may have limited results (Gall et al., 2007). While we counterbalanced the dyads with one TEEACH graduate and one non-TEEACH graduate, the TEEACH graduate could have influenced the other dyad member. Because the first author served as the eCoach and primary observer (coder) for the study, researcher bias may have limited the results. Moreover, the trained inter-rater reliability observer was not naïve to the purpose of the research and therefore may have identified expected behaviors that were not present (Gall et al., 2007). Stability in baseline (Kratochwill et al., 2010; Lane, Wolery, Reichow, \& Rogers, 2007) was also a concern. Due to time constraints, instead of continuing baseline conditions until all dyads met requirements for an absence in trend, the intervention phase was introduced when at least one dependent variable met the requirement for each dyad. Moreover, we collected only four data points in each phase of the study. Therefore, according to Kratochwill et al. (2010), this study meets standards with reservation. As mentioned previously, the results may be limited by reversibility in withdrawal. A multiple baseline design was rejected yet may have provided more salient outcomes. 
Finally, PND calculations ignore all baseline data except for one point, and that point may be unreliable (i.e., an outlier). In such cases, the effect of the intervention may be greater than calculated by PND (Kazdin, 2011).

\section{Implications for Research}

In theory, the benefits of co-teaching should far outweigh the barriers to its implementation (Friend et al., 2010). The theoretical benefits (e.g., higher student teacher interactions, individualized instruction) of co-teaching have not been evident in the majority of the coteaching research (i.e., Friend et al., 2010; Magiera \& Zigmond, 2005; Moin et al., 2008; Murawski, 2006). Therefore, future researchers should continue investigating innovations that assist general and special educators in realizing theorized benefits. Specifically, future researchers should investigate the effects of eCoaching on the hallmarks of special education noted by B. G. Cook and colleagues (2011).

The limitations of this study confirm further replication should be conducted. For instance, future co-teaching researchers should strive to include larger samples of co-teacher participants who have not had previous experience with eCoaching. More research should also be completed to examine the effectiveness of eCoaching with co-teacher partners over extended periods and the maintenance of acquired co-teaching skills when eCoaching is withdrawn. Maintenance and generalization data collected over longer periods in diverse settings would help establish longlasting acquisition of newly acquired co-teaching skills.

Studies should also be conducted to tease out the effects of eCoaching during planning and instruction (i.e., eCoaching during both planning and instruction, eCoaching during planning sessions only, and eCoaching during co-taught instruction only). Participants in this study indicated eCoaching during planning may be an efficient intervention in and of itself. Consequently, eCoaching during actual instruction may not be needed to increase desired coteaching behaviors. More research is needed to confirm this anecdote.

\section{Conclusion}

Without question, teachers need opportunities to observe collaboration, attempt the act of coteaching in practice, and receive feedback on their efforts during training (Brownell, Ross, Colón, \& McCallum, 2005; Stang \& Lyons, 2008). In many cases, however, teachers are left to improve co-teaching practices on their own (Kamens, 2007). Although modeling of co-teaching during professional development workshops is a step in the right direction, it has been only moderately effective in changing co-teaching practices in the field. The current study increases understanding of the effects of job embedded co-teaching training. To our knowledge, no other researchers have supported participants with eCoaching while they planned and implemented varied co-teaching models, planned and provided student-specific accommodations and modifications, and planned and implemented PBIS strategies. Finally, we found that eCoaching increased teachers' implementation of specific, coached strategies (i.e., variation in co-teaching 
approaches, inclusion of positive behavioral supports, etc.). While this research shows that in the absence of BIE technology these behaviors decreased, it can be hypothesized that the more opportunities that teachers have to practice these desirable practices, the more likely these behaviors will become a part of a teacher's repertoire (future behavior) in the absence of eCoaching. The results of this study, although by no means definitive, confirmed the efficacy of eCoaching as an effective approach to supporting new co-teachers in bridging the gap between research and practice.

\section{Declaration of Conflicting Interests}

The author(s) declared no potential conflicts of interest with respect to the research, authorship, and/or publication of this article.

\section{Funding}

The author(s) received no financial support for the research, authorship, and/or publication of this article.

\section{References}

Alberto, P. A., \& Troutman, A. C. (2003). Applied behavior analysis for teachers (6th ed.). Upper Saddle River, NJ: Prentice Hall.

Baker, J. M., \& Zigmond, N. (1995). The meaning and practice of inclusion for students with learning disabilities: Themes and implications for the five cases. Journal of Special Education, 29, 163-180.

Barlow, D. H., Nock, M. K., \& Hersen, M. (2009). Single case experimental designs: Strategies for studying behavior change (3rd ed.). Boston, MA: Pearson.

Brinkmann, J., \& Twiford, T. (2012). Voices from the field: Skill sets needed for effective collaboration and co-teaching. International Journal of Educational Leadership Preparation, 7(3), 1-13.

Brownell, M. M., Ross, D. D., Colón, E. P., \& McCallum, C. L. (2005). Critical features of special education teacher preparation: A comparison with general teacher education. The Journal of Special Education, 38, 242-252.

Bryant Davis, K. E., Dieker, L. A., Pearl, C., \& Kirkpatrick, R. M. (2012). Planning in the middle: Co-planning between general and special education. Journal of Educational \& Psychological Consultation, 22, 208-226. doi: 10.1080/10474412.2012.706561

Cook, B. G., McDuffie-Landrum, K. A., Oshita, L., \& Cothren Cook, S. (2011). Co-teaching for students with disabilities: A critical analysis of the empirical literature. In J. Kauffman \& D. P. Hallahan (Eds.), Handbook of special education (pp. 147-159). New York, NY: Routledge. 
Cook, L., \& Friend, M. (1995). Co-teaching: Guidelines for creating effective practices. Focus on Exceptional Children, 28(3), 1-16.

Croft, A., Coggshall, J. G., Dolan, M., Powers, E., \& Killion, W. J. (2010, April). Job-embedded professional development: What it is, who is responsible, and how to get it done well (Issue Brief). Washington, DC: National Comprehensive Center for Teacher Quality.

Curtin, J. P. (1998). A case study of co-teaching in an inclusive secondary classroom. Dissertation Abstracts International, 60(01), 31A. (UMI No. AAG9917397)

Dettmer, P., Thurston, L. P., \& Dyck, N. (2005). Consultation, collaboration, and teamwork for students with special needs (4th ed.). Boston, MA: Allyn \& Bacon.

Dieker, L. A. (2001). What are the characteristics of "effective" middle and high school cotaught teams for students with disabilities? Preventing School Failure, 46, 14-23.

Dieker, L. A. (2002). The co-teaching lesson plan book (3rd ed.). Whitefish Bay, WI: Knowledge by Design.

Fennick, E., \& Liddy, D. (2001). Responsibilities and preparation for collaborative teaching: Coteacher's perspectives. Teacher Education and Special Education, 24, 229-240.

Friend, M. (Co-producer with Burrello, L., \& Burrello, J.). (2005). The power of two: Including students through co-teaching (2nd ed.) [videotape]. Bloomington, IN: Elephant Rock Productions.

Friend, M., \& Cook, L. (2003). Interactions collaboration skills for school professionals $\left(^{\text {th }}\right.$ ed.). Boston, MA: Allyn \& Bacon.

Friend, M., Cook, L., Hurley-Chamberlain, D., \& Shamberger, C. (2010). Co-teaching: An illustration of the complexity of collaboration in special education. Journal of Educational and Psychological Consultation, 20, 9-27.

Gall, M. D., Gall, J. P., \& Borg, W. R. (2007). Educational research: An introduction (8th ed.). Boston, MA: Allyn \& Bacon.

Gast, D. L. (2010). Single subject research methodology in behavioral sciences. New York, NY: Routledge.

Gould, A., \& Vaughn, S. (2000). Planning for the inclusive classroom: Meeting the needs of diverse learners. Catholic Education: A Journal of Inquiry and Practice, 3, 363-374.

Gurgur, H., \& Uzuner, Y. (2011). Examining the implementation of two co-teaching models: Team teaching and station teaching. International Journal of Inclusive Education, 15, 589-610. 
Harbort, G., Gunter, P. L., Hull, K., Brown, Q., Venn, M. L., Wiley, L. P., \& Wiley, E. W. (2007). Behaviors of teachers in co-taught classes in a secondary school. Teacher Education and Special Education, 30, 13-23.

Horner, R. H., Carr, E. G., Halle, J., McGee, G., Odom, S., \& Wolery, M. (2005). The use of single-subject research to identify evidence-based practice in special education. Exceptional Children, 71, 165-179.

Individuals With Disabilities Education Improvement Act of 2004, U.S.C. §§ 1400 et seq. (2004).

Joyce, B., \& Showers, B. (2002). Student achievement through staff development (3rd ed.). Alexandria, VA: Association for Supervision and Curriculum Development.

Kamens, M. W. (2007). Learning about co-teaching: A collaborative student teaching experience for preservice teachers. Teacher Education and Special Education, 30, 155-166.

Kazdin, A. E. (2011). Single-case research designs: Methods for clinical and applied settings (2nd ed.). New York, NY: Oxford University Press.

Keefe, B., \& Moore, V. (2004). The challenge of co-teaching in inclusive classrooms at the high school level and what the teachers told us. American Secondary Education, 32, 77-78.

Kennedy, C. H. (2005). Single-case designs for educational research. Boston, MA: Pearson.

Korner, I. N., \& Brown, W. H. (1952). The mechanical third ear. Journal of Consulting Psychology, 16, 81-84.

Kratochwill, T. R., Hitchcock, J., Horner, R. H., Levin, J. R., Odom, S. L., Rindskopf, D. M., \& Shadish, W. R. (2010). Single-case designs technical documentation. Retrieved from http://ies.ed.gov/ncee/wwc/pdf/reference_resources/wwc_scd.pdf

Lane, K., Wolery, M., Reichow, B., \& Rogers, L. (2007). Describing baseline conditions: Suggestions for study reports. Journal of Behavior Education, 16, 224-234.

Leko, M. M., \& Brownell, M. T. (2009). Professional development for special educators: What school leaders should know. TEACHING Exceptional Children, 42(1), 64-70.

Levin, J. R., O’Donnell, A. M., \& Kratochwill, T. R. (2003). Educational/psychological intervention research. In W. Reynolds \& G. Miller (Eds.), Handbook of psychology, Vol. 7: Educational psychology (pp. 557-581). Hoboken, NJ: John Wiley.

Magiera, K., Smith, C., Zigmond, N., \& Gerbauer, K. (2005). Benefits of co-teaching in secondary mathematics classes. TEACHING Exceptional Children, 37(3), 20-24. 
Magiera, K., \& Zigmond, N. (2005). Co-teaching in middle school classrooms under routine conditions: Does the instructional experience differ for students with disabilities in co-taught and solo-taught classes. Learning Disabilities Research \& Practice, 20, 79-85.

Mastropieri, M., Scruggs, T., Graetz, J., Norland, J., Gardiizi, W., \& McDuffie, K. (2005). Case studies in co-teaching in the content areas: Successes, failures, and challenges. Intervention in School and Clinic, 40, 260-270.

Moin, L. J., Magiera, K., \& Zigmond, N. (2008). Instructional activities and group work in the US inclusive high school co-taught science class. International Journal of Science and Math Education, 7, 677-697.

Morocco, C. C., \& Aguilar, C. M. (2002). Co-teaching for content understanding: A school wide model. Journal of Educational and Psychological Consultation, 13, 315-347.

Murawski, W. W. (2006). Student outcomes in cotaught secondary English classes: How can we improve? Reading \& Writing Quarterly: Overcoming Learning Difficulties, 22, 227-247.

Murawski, W. W. (2008). Five keys to co-teaching in inclusive classrooms. The School Administrator, 8(65), 28-31.

Murawski, W. W., \& Swanson, H. L. (2001). A meta-analysis of the co-teaching research: Where are the data? Remedial and Special Education, 22, 258-267.

National Center for Learning Disabilities. (2006). Accommodations for students with learning disabilities. Retrieved from www.ldonline.org/article/Accommodations_for_Students_with_LD

Pancsofar, N., \& Petroff, J. G. (2013). Professional development experiences on co-teaching: Associations with teacher confidence, interests, and attitudes. Teacher Education and Special Education, 36, 83-96.

Pearl, C., Dieker, L. A., \& Kirkpatrick, R. M. (2012). A five-year retrospective on the Arkansas department of education co-teaching project. Professional Development in Education, 38, 571587. doi:10.1080/19415257.2012.668858

Rea, P. J., McLaughlin, V. L., \& Walther-Thomas, C. (2002). Outcomes for students with learning disabilities in inclusive and pullout programs. Exceptional Children, 68, 203-222.

Rice, B. A., \& Zigmond, N. (2000). Co-teaching in secondary schools: Teacher reports of development in Australian and American classrooms. Learning Disabilities Research \& Practice, 15, 190-197.

Rock, M. L., Gregg, M., Gable, R., Zigmond, N., Blanks, B., Howard, P. A., \& Bullock, L. (2012). Time after time online: An extended study of virtual coaching during distant clinical practice. Journal of Technology and Teacher Education, 20, 277-304. 
Rock, M. L., Gregg, M., Thead, B. K., Acker, S., Gable, R., \& Zigmond, N. (2009). Can you hear me now? Evaluation of an online wireless technology to provide real-time feedback to special education teachers-in-training. Teacher Education and Special Education, 32, 64-82.

Rock, M. L., Zigmond, N. P., Gregg, M., \& Gable, R. A. (2011). The power of virtual coaching. Educational Leadership, 69(2), 42-47.

Rooney, J. (2007). Who owns teacher growth? Educational Leadership, 64(7), 87-88.

Scheeler, M. C., Congdon, M., \& Stansbery, S. (2010). Providing immediate feedback to coteachers through bug-in-ear technology: An effective method of peer coaching in inclusion classrooms. Teacher Education and Special Education, 33, 83-96.

Scheeler, M. C., Ruhl, K. L., \& McAfee, J. K. (2004). Providing performance feedback to teachers: A review. Teacher Education and Special Education, 17, 396-407.

Scruggs, T. E., \& Mastropieri, M. A. (1998). Summarizing single case research: Issues and applications. Behavior Modification, 22, 221-242.

Scruggs, T. E., Mastropieri, M. A., \& Castro, G. (1987). The quantitative synthesis of single subject research: Methodology and validation. Remedial and Special Education, 8, 24-33.

Scruggs, T. E., Mastropieri, M. A., \& McDuffie, K. A. (2007). Co-teaching in inclusive classrooms: A metasynthesis of qualitative research. Exceptional Children, 73, 392-416.

Simonsen, B., Myers, D., \& DeLuca, C. (2010). Teaching teachers to use prompts, opportunities to respond, and specific praise. Teacher Education and Special Education, 33, 300-318.

Sindelar, P. T., Brownell, M., \& Billingsley, B. (2010). Special education teacher education research: Current status and future directions. Teacher Education and Special Education, 33, 824.

Smith, T. E., Polloway, E., Patton, J. R., \& Dowdy, C. A. (2008). Teaching students with special needs in inclusive settings (5th ed.). Boston, MA: Pearson.

Spooner, F., Algozzine, B., Wood, C. L., \& Hicks, S. C. (2010). What we know and need to know about teacher education and special education. Teacher Education and Special Education, $33,44-54$.

Stang, K., \& Lyons, B. M. (2008). Effects of modeling collaborative teaching for pre-service teachers. Teacher Education and Special Education, 31, 182-194.

Steele, D. (1995). Gentle teaching: A value based framework for helping others (ERIC Document Reproduction Service No. ED381983). Retrieved from http://files.eric.ed.gov/fulltext/ED381983.pdf. 
Tankersley, M., Harjusola-Webb, S., \& Landrum, T. (2008). Using-single-subject research to establish the evidence base of special education. Intervention in School and Clinic, 44, 83-90.

U.S. Department of Education. (2008). OSEP's annual report to congress on implementation of Individuals With Disabilities Education Act (IDEA). Retrieved from

http://www2.ed.gov/about/reports/annual/osep/2008/partsb-c/30th-idea-arc.pdf

Volonino, V., \& Zigmond, N. (2007). Promoting research-based practices through inclusion? Theory into Practice, 46, 291-300.

Walsh, J. M. (2012). Co-teaching as a school system strategy for continuous improvement. Preventing School Failure, 56, 29-36.

Walther-Thomas, C. S., \& Bryant, M. (1996). Planning for effective co-teaching. Remedial and Special Education, 17, 255-266.

Walther-Thomas, C. S., Korinek, L., McLaughlin, V. L., \& Williams, B. T. (2000).

Collaboration for inclusive education: Developing successful programs. Boston, MA: Allyn \& Bacon.

Weiss, M. P., \& Lloyd, J. L. (2002). Congruence between roles and actions of secondary special educators in co-taught and special education settings. Journal of Special Education, 36, 58-69.

Zigmond, N. (2001). Special education at the crossroads. Preventing School Failure, 45, 70-74.

Zigmond, N., \& Baker, J. (1995). The meaning and practice of inclusion for students with learning disabilities [Special issue]. The Journal of Special Education, 29, 163-180.

\section{Author Biographies}

Donna M. Ploessl is an assistant professor in the Department of Education at Stillman College. Her research interests include collaboration, co-teaching, eCoaching, and pre-service teacher education.

Marcia L. Rock is an associate professor and director of doctoral studies in the Department of Specialized Education Services at the University of North Carolina Greensboro. Her primary research interests include eCoaching (referrred to formerly as virtual coaching), technology enabled teacher development, classroom/behavior management, and strategic self-regulation. 